\title{
Two Kinds of Unity in the Critique of Pure Reason
}

\author{
C O L I N M C LEAR*
}

ABSTRACT I argue that Kant's distinction between the cognitive roles of sensibility and understanding raises a question concerning the conditions necessary for objective representation. I distinguish two opposing interpretive positions, namely Intellectualism and Sensibilism. According to Intellectualism, all objective representation depends, at least in part, on the unifying synthetic activity of the mind. In contrast, Sensibilism argues that at least some forms of objective representation, specifically intuitions, do not require synthesis. I argue that there are deep reasons for thinking that Intellectualism is incompatible with Kant's view as expressed in the Transcendental Aesthetic. We can better see how Kant's arguments in the first Critique may be integrated, I suggest, by examining his notion of the "unity" (Einheit) of a representation. I articulate two distinct ways in which a representation may possess unity and claim that we can use these notions to integrate Kant's arguments in the Aesthetic and the Transcendental Deduction without compromising the core claims of either Sensibilism or Intellectualism - that intuition is a form of objective representation independent of synthesis, and that the kind of objective representations that ground scientific knowledge of the world require synthesis by the categories.

KEYWORDS Concepts; conceptualism; Immanuel Kant; intuition; non-conceptualism; perception; space; synthesis; transcendental deduction; unity

Space is not an existing object of sensible intuition, nor-as little as time-is it something existing outside me, in which the manifold of perceptions is determinable as to its position, rather [space and time are] themselves intuitions given a priori, which contain in themselves, synthetically a priori, the formal principle of the composition of the manifold in appearance. Limitless with regard to their extensive magnitude, they hence contain unconditional unity (and thus infinity); there is only one space and one time. (Opus Postumum, 22:12) ${ }^{\mathrm{I}}$

${ }^{1}$ Quotations from Kant's work are from the Akademie Ausgabe, with the first Critique cited by the standard A/B edition pagination, and the other works by volume and page. Translations are my own, though I have regularly consulted translations from the Hackett editions by Werner Pluhar and the Cambridge Editions of the Works of Immanuel Kant, general editors Paul Guyer and Allen Wood. Specific texts are abbreviated as follows:

An: Anthropology from a Pragmatic Point of View

BL: Blomberg Logic

* Colin McLear is Assistant Professor of Philosophy at the University of Nebraska-Lincoln.

Journal of the History of Philosophy, vol. 53, no. I (2015) 79-I IO 
KANT FAMOUSLy Distinguishes BETWEen TWO distinct cognitive faculties, namely "sensibility" (Sinnlichkeit) and "understanding" (Verstand), whose joint operation allows for Erkenntnis or "cognition" to occur. Consider, for example, his introduction of the distinction at the beginning of the Transcendental Aesthetic of the first Critique:

Objects are given to us by means of sensibility, and it alone yields us intuitions; they are thought through the understanding, and from the understanding arise concepts. (Ar9/B33; cf. B33/Ar9, A5I/B75)

Here we have a distinction between the cognitive roles of the two faculties in giving (sensibility) and thinking about (understanding) objects. If we construe this "givenness" in terms of having an objective representation-that is, a representation of some mind-independent feature of reality—then Kant appears committed to a fairly straightforward division of cognitive labor. ${ }^{2}$ Sensibility furnishes the mind with objective representations (intuitions) and the understanding allows for thought of what is objectively represented in intuition. ${ }^{3}$

However, Kant's argumentative strategy in the Transcendental Deduction appears to complicate this seemingly straightforward separation of the faculties' cognitive roles. In the Deduction, Kant hopes to show that the a priori concepts he calls the "categories" have legitimate application to objects of experience. The strategy by which he intends to achieve this result has been interpreted by many as requiring that the categories play a necessary role in being given an object. ${ }^{4}$ For example, Kant clearly states in the conclusion of the argument of the Deduction that the categories are the "conditions of the possibility of experience" (BI 6I). This would seem to deny the possibility of any objective representation without the categories.

\author{
C: Correspondence \\ CJ: Critique of Judgment \\ FI: First Introduction to CJ \\ JL: Jäsche Logic \\ LL: Lectures on Logic \\ MFNS: Metaphysical Foundations of Natural Science \\ Pr: Prolegomena to any Future Metaphysics \\ $R$ : Reflections and Fragments
}

${ }^{2}$ For a similar gloss of objective representation, see Pereboom, "Kant's Deductions," I 60. I leave open here exactly how Kant understands the mechanism for objective representation. For example, it might be that objective representations are those representations that possess correctness conditions of some kind. We might further explain the possession of correctness conditions in virtue of causal covariance between representations and states of the subject's environment. I discuss these issues further in "Kant on Animal Consciousness" and "Kant on Perceptual Content"; see also the discussion in $\S 3$ below.

${ }^{3}$ Cf. Pritchard, Kant's Theory of Knowledge, 28. I should also note that here and throughout I am primarily concerned with objective representation in finite beings. The intellectual intuitions by which God represents objective matters are another story. I briefly discuss this issue further in $\S \mathrm{I}$ below

${ }^{4}$ Notable proponents of this view include Strawson, The Bounds of Sense; Sellars, Science and Metaphysics; Pippin, Kant's Theory of Form; Guyer, Kant and the Claims of Knowledge; Pereboom, "Kant on Intentionality"; Kitcher, Kant's Transcendental Psychology and Kant's Thinker, McDowell, Mind and World, "The Logical Form of an Intuition," "Hegel and the Myth," and "Intentionality as a Relation"; Longuenesse, Kant and the Capacity to Judge; Van Cleve, Problems from Kant; Engstrom, "Understanding and Sensibility"; Ginsborg, "Kant and the Problem of Experience"; Land, "Kant's Spontaneity Thesis" and "Prescribing Unity to Intuition"; Pereboom, Kant's Deductions; Haag, Erfahrung und Gegenstand; Grüne, Blinde Anschauung; Griffith, "Perception and the Categories." 
More generally, Kant's argument in the Deduction appears to make objective representation dependent on a particular kind of mental activity, which Kant terms "synthesis": the running through, gathering together, and building up of discrete bits of data into a unified state of awareness of an object, property, or state-of-affairs (A77-79/BI02-5).

Using the notion of synthesis, we can distinguish two very general positions regarding the cognitive roles of sensibility and the understanding. Either sensibility, independently of any synthesis, furnishes the mind with objective representations (intuitions), or such objective representations depend, at least in part, on mental acts of synthesis. ${ }^{5}$ Call the position that sensibility may furnish the mind with at least some unsynthesized objective representations "Sensibilism." This position contrasts with one-call it "Intellectualism"-that says that all objective representation requires synthesis. ${ }^{6}$

As interpreters, we must wonder which view-Sensibilism or Intellectualism-is Kant's view. In what follows, I claim that Kant's arguments in the Transcendental Aesthetic concerning the structure and nature of our representations of time and space are incompatible with Intellectualism.

Indeed, several interpreters have noted that there seems to be an incompatibility between the claims of the Aesthetic and subsequent parts of the Transcendental Analytic. They have therefore suggested that, once Kant's commitments in subsequent sections of the first Critique (especially the Transcendental Deduction) have been made clear, we must reread or otherwise recast his arguments in the Aesthetic in the light of the requirements set by his articulation of the nature of synthesis. ${ }^{7}$ In short, they argue that we must reread the argument of the Aesthetic in an Intellectualist manner. I believe that such a proposed rereading is mistaken.

If the argument I present in $\$ 2$ below is correct, then we cannot give an Intellectualist rereading of Kant's argument in the Transcendental Aesthetic without compromising central tenets of the critical philosophy. This appears to leave us at a significant interpretive impasse. On the one hand, we are faced with the possibility that Kant's critical philosophy is an incoherent blend of Sensibilist and

${ }^{5}$ A protracted debate in Kant studies concerns whether Kant is a "conceptualist"-one who regards the content of perceptual experience as wholly conceptual. However, there are a variety of ways in which one might construe the content of an experience as conceptual (cf. Heck, "Nonconceptual Content"; Speaks, "Is There a Problem?"), and a variety of ways in which Kant utilizes the notion of a "concept" in his arguments regarding the relation between the two stems or faculties of cognitionviz. sensibility and understanding (cf. Hanna, "Kant and Nonconceptual Content"). Fortunately, we can separate the question of whether intuitions have conceptual content from whether intuition, insofar as it is objective representation, depends on the synthetic (whether understood as conceptual or not) activity of the intellect (my catch-all term for those faculties of the mind that are "higher" or more cognitively sophisticated than sensibility). It is this latter question that I focus on in this paper. For further discussion of the conceptualism debate with respect to Kant, see McLear, "The Kantian (Non)-Conceptualism Debate."

${ }^{6}$ See Burge's Origins of Objectivity for an extremely critical discussion of forms of Intellectualism concerning perceptual representation in the twentieth century. I am not concerned here with whether Intellectualism is false, but rather how best to understand Kant.

${ }^{7}$ Longuenesse (Capacity to Judge, ch. 8) discusses the importance of carrying out this "rereading" of the Aesthetic. Cf. Natorp, Grundlagen; Pippin, Kant's Theory ofForm; Sedgwick, "McDowell's Hegelianism"; Abela, Kant's Empirical Realism; Wenzel, "Die Categorien"; Ginsborg, "Was Kant a Nonconceptualist?" 
Intellectualist ideas. On the other hand, Sensibilism may seem unable to account for a central and surely correct insight of interpreters attracted to Intellectualism, namely that synthesis figures prominently in Kant's account of rational human cognition. However, I believe we can integrate Kant's arguments in the Aesthetic and the Deduction without compromising the core claims of either side: that intuition is a form of objective representation independent of synthesis, and that the kind of objective representations that ground scientific knowledge of the world require synthesis by the categories.

We can better see how Kant's arguments in the first Critique may be integrated, I suggest, by examining his notion of the "unity" (Einheit) of a representation. I articulate two distinct ways in which a representation may possess unity. One is aesthetic and given via sensibility. ${ }^{8}$ The other is discursive and generated by the understanding. ${ }^{9}$ Insofar as intuition has aesthetic unity, it counts as a form of objective representation. If, however, it is granted that intuition has aesthetic unity, the question arises as to why the understanding, and particularly the categories, might be necessary for the generation of experience. In the second half of the paper I sketch an answer to this question by explicating the second notion of unity-namely, "discursive unity" - which I suggest is the notion of unity at issue in the argument of the Transcendental Deduction. I claim that the Deduction's argument concerning discursive unity is no threat to the conception of aesthetic unity laid out in the Transcendental Aesthetic, and thus no threat to the Sensibilist claim that intuition is a non-synthesized form of objective representation. I then discuss how these aesthetic and discursive unities relate in the perceptual experience of an object.

This paper consists of four sections. Section one examines in further detail the Intellectualist argument for the dependence of aesthetic unity, or the unity of intuition, on the intellect. Section two presents, in two steps, my argument against the existence of such a dependence relation based on Kant's characterizations of intuition and the discursive activity of the mind. I also address an objection to my argument that stems from Kant's conception of our cognition of totalities. Section three discusses the notion of discursive unity and the compatibility of aesthetic unity, as I have articulated it, with Kant's argument in the Transcendental Deduction. Finally, in section four, I summarize the paper as a whole.

\section{THE IN TELLECTUALIST ARGUMENT FOR THE PR I M A Y OF D I C URS I E U N I T Y}

In the Transcendental Aesthetic Kant makes the case for thinking that sensory consciousness has certain formal features, which are present in any sensory

\footnotetext{
${ }^{8}$ Here and throughout I use 'aesthetic' in the sense that Kant uses it in the first Critique-viz. as having to do with our receptive faculty of cognition, and not with the issue of beauty or taste; see A2I/B35, note.

'I use 'discursive' here and throughout to denote the manner in which the understanding acts—viz. moving to and fro, from part to part-rather than merely as a synonym for 'conceptual,' 'linguistic,' or 'rational.' Perhaps the clearest example of the understanding's activity is in combining conceptual representations into a whole unified propositional judgment. Kant is clear, however, that the understanding works upon more than just concepts; most significantly, for our purposes, is that it works on sensory representations as well. I discuss and defend this claim further in $\$ \S 2-3$ below.
} 
experience. These features consist in the spatial and temporal manner in which things are sensorily presented (A20/B34).

The Intellectualist argument I am about to discuss is an abstraction. Nevertheless I believe it accurately captures the interpretive positions of a wide group. ${ }^{\text {I0 }}$ The textual basis for the argument comes primarily from the Metaphysical and Transcendental Deductions, and concludes that a necessary condition for an intuition's being an intuition-namely, a "unified" objective representation of some entity (either a property, object, or state-of-affairs) - is the activation of the subject's discursive capacities in an act of synthesis.

I understand the Intellectualist argument as follows:

I. An intuition must have unity if it is to present a particular to a conscious subject.

2. Both intuition and judgment have a common source of unity, namely, discursive synthesis.

3. The categories are the most general expressions of this discursive unity.

4. $\therefore$ The unity of an intuition requires the unity provided by the categories.

I want to note two caveats about this argument.

First, the argument concerns only the intuitions of discursive beings. God's intuition is intellectual but it is not discursive. Hence God's intuitive cognition does not rely on a discursive synthesis. ${ }^{\text {I }}$

Second, there may be questions concerning the notion of "unity" at work in this argument. Kant often speaks of the "unity of the manifold" of intuition (cf.

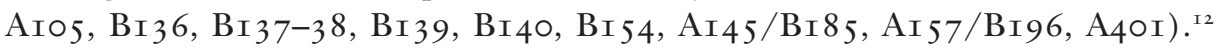
$\mathrm{By}$ this he means the connection or relatedness of individual representational elements together in one consciousness. So an intuition must have unity insofar as it is a single-though perhaps complex-sensory representation of an object, property, or state-of-affairs.

In a key passage from the Metaphysical Deduction, Kant claims that the unity of judgment-itself a form of objective representation-and the unity of intuition have a common ground or explanation. ${ }^{\mathrm{I}}$ He says,

The same function that gives unity to the different representations in a judgment also gives unity to the mere synthesis of different representations in an intuition, which, expressed generally, is called the pure concept of understanding. The same

\footnotetext{
${ }^{10}$ Some examples of versions of this argument include Strawson, The Bounds of Sense, 56-57; McDowell, "Hegel and the Myth," 80-83; Guyer, "The Deduction of the Categories," I46. For other examples, see the sources cited in note 4 above.

${ }^{11}$ Kant links discursivity to conceptual articulation in countless places. See, for example, Axviixviii, A24-5/B 39, A3 I-32/B 47, A230/B283, A7I9/B 747; CJ 5:406. He discusses the non-discursive intuitive intellect of God most strikingly in $C J \S 77,5: 407-8$. One might pursue an argument against conceptualism on the basis of this view of intellectual intuition, since intellectual intuition does not depend for its unity on concepts, but I will not do so here.

${ }^{12}$ The emphasis on the unity of the manifold makes it potentially ambiguous as to whether what requires unity is the form of an intuition or the intuition's matter. I take it that Intellectualism argues that the unity issue applies to both. Longuenesse, for example, is clear that the form of an intuition (i.e. its spatial and temporal nature) relies on intellectual activity (specifically affection of sensibility by the understanding), while the unity of its matter, as a sensory image, relies on rule-governed construction in imagination; see Longuenesse, Capacity to Judge, ch. 3; and Human Standpoint, chs. 2 \& 3.

${ }^{13}$ For discussion of intuition and judgment as forms of objective representation, see A68/B93, A320/B376-77.
} 
understanding, therefore, and indeed by means of the very same actions through which it brings the logical form of a judgment into concepts by means of the analytical unity, also brings a transcendental content into its [the understanding's] representations by means of the synthetic unity of the manifold in intuition in general, on account of which they are called pure concepts of the understanding that pertain to objects a priori. (A79/BIO4-5)

Though this is a difficult passage, the important point for the Intellectualist interpretation is that Kant here links the manner of uniting representations (specifically, concepts) in a judgment with the manner of uniting representations (perhaps understood by the Intellectualist as sensations) in an intuition. The Intellectualist interpretation of the passage thus construes the notion of judgmental unity in terms of the presence of a logical form (e.g. subject-predicate form), which distinguishes a judgment (e.g. 'The ball is red') from a mere list of concepts (e.g. $<$ the ball $>,<$ red $>$ ). Since, according to the passage, the very same function is involved in giving unity to both intuition and judgment as forms of objective representation, the claim seems to be that logical form is present in both judgment and intuition due to the intellectual or conceptual activity of the subject. It is the presence of this logical form that is necessary for crediting the subject with an objective awareness (in both thought and experience) of her environment. ${ }^{\mathrm{I}}$

The Intellectualist thus construes the $\mathrm{A}_{79} / \mathrm{BIO}_{4}-5$ passage as direct evidence for Kant's endorsing premise (2). Kant is then taken as arguing for premises (2) and (3) through the course of the Transcendental Deduction, in order to demonstrate that the categories are necessary even in the case of the unity of intuition.

The argument of the Deduction comes to a head in $\$ 26$, where Kant again explicitly connects the unity of intuition to the categories. He says,

\begin{abstract}
Space and time are not merely forms of sensory intuition, rather they are intuitions themselves (which contain a manifold), and therefore are represented with the determination of the unity of this manifold in them a priori (see the Transcendental Aesthetic). Hence, everything without or within us, consequently also the combination of all that shall be represented as determined in space or time, must conform to the unity of the synthesis of the manifold as a condition of the synthesis of all apprehension already given a priori with (not in) this intuition. This synthetic unity can be none other than the combination of the manifold of a given intuition in general in an original consciousness, in conformity with the categories, only applied to our sensory intuition. It follows that all synthesis, through which perception itself becomes possible, stands under the categories, and since experience is cognition through connected perceptions, the categories are the conditions of the possibility of experience, and are therefore also valid a priori for all objects of experience. (BI6I-62; my emphasis)
\end{abstract}

According to Intellectualism, Kant argues here that space and time are not merely the forms of intuition, they are also individuals represented in intuition, whose multiplicity of representational parts (i.e. discrete times and spaces) stand in need of unification. Here and in a crucial, though much debated, footnote to the

${ }^{14}$ For interpretations of this passage along these lines, see e.g. Longuenesse, Capacity to Judge; McDowell, "Hegel and the Myth." Land argues for a "two-species" notion of discursive unity as encompassing both judgmental and sensible synthesis. Land thinks that intuition must be "determined" according to one of the logical forms of judgment in order to count as a form of objective awareness ("Kant's Spontaneity Thesis," 200). 
passage (on which more below), Kant is taken to argue that the categories play an essential role in the representational unity of time and space as forms of intuition. Since these forms are necessary for anything that may perceptually appear to us, by showing that the categories are necessary for the unity of the forms of intuition, Kant thereby demonstrates their necessity for perceptual representation more generally. ${ }^{\mathrm{I}}$

In sum, the Intellectualist interprets Kant as arguing that the unity of an intuition depends on its having a logical form or structure, and that the same process that gives structure to judgment also structures intuition. Note that this need not require that judgment $i t s e l f$ structures intuition, that is, that intuition be taken as a form of judgment or as propositional in structure. Instead, Intellectualism can claim, more broadly, that no mental state counts as a form of objective representation unless the subject has discursive capacities that are brought to bear in synthesizing some bit of given sensible data into a unified representation of the subject's environment. These capacities may be engaged directly, in the form of judgment, or indirectly, in the form of rules for the sensible synthesis of given sensory input. In either case, intervention on the part of a higher cognitive faculty is required for there to be objective representation in the intuition of a particular property, object, or state-of-affairs. Hence, the core Intellectualist idea is that the capacity for intuition to function as an immediate and singular objective representation depends on discursive activity in one form or another. ${ }^{16}$

The Intellectualist reading of the passages discussed above, and others like them, provides a powerful and, at least for the purposes of understanding the argument of the Deduction, seemingly fruitful reading of central elements of Kant's critical philosophy. ${ }^{17}$ But as I shall argue, the truth of premise (2) - that both intuition and judgment have a common source of unity in the discursive activity of the understanding-is incompatible with central elements of Kant's arguments for the intuition of space and time. Kant presents these arguments in

${ }^{15}$ For some representative statements of this kind of interpretive strategy, see Longuenesse, Capacity to Judge; McDowell, "Hegel and the Myth"; Griffith, "Perception and the Categories"; Guyer, "The Deduction of the Categories."

${ }^{16}$ Though I have emphasized textual motivations for this interpretation, there are non-textual ones as well. One motivation, broadly put, is that the only way to make sense of sensory experience as being about the world is if it has the same structure as something we unproblematically (or at least less problematically) think of as being about the world, namely thought and language. Without the logical structure inherent in our thought and language, sensory experience would be mere sensory chaos. This opposition between sensory chaos and conceptual structure is present in several of Kant's commentators, as well as people influenced by Kant. See, for example, Lewis, Mind and the World-Order; Sellars, "Kant's Views"; Pereboom, "Kant on Intentionality"; Van Cleve, Problems from Kant; Haag, Erfahrung und Gegenstand; Grüne, Blinde Anschauung. McDowell ("Hegel and the Myth," 80) argues that intuition and judgment are to be understood as reciprocally shedding light upon each other, but his exposition seems to heavily favor the intelligibility of judgment as a form of objective awareness over that of sensory consciousness.

${ }^{17}$ While I do not consider the two passages quoted above to be the only passages that suggest an Intellectualist position, they are certainly two of the most significant. I discuss a third passage-the controversial footnote to $\$ 26$ of the B-Deduction-in $\$ 2$.I below. Another important passage, which I will not discuss here, appears at $\mathrm{B}_{\mathrm{I}} 37$ in $\S \mathrm{I} 7$ of the B-Deduction argument. There Kant defines an object as "the concept in which the manifold of a given intuition is united." This suggests that cognitive relation to an object must call upon an intellectual synthesis of some kind or another. I will discuss this passage in future work. 
both editions of the Transcendental Aesthetic, though I will concentrate on the B-edition formulations. ${ }^{18}$ This will occupy us in the next section.

2. A ESTHETIC UN T T A N D D I C URSIVE GRASP

Kant famously argues in the Transcendental Aesthetic that space and time are a priori representations. For our purposes, the interesting characteristic of these representational forms is that we grasp them wholly non-discursively. We are aware of them as singular and infinite given wholes, and this awareness is presupposed in order to account for our awareness of particular times (moments) or spaces (locations), which Kant describes as mere "limitations" (A25/B39, A32/B47) of the wholes of space and time. He claims that this demonstrates that space and time are intuitive rather than conceptual representations. In what follows, I shall consider these arguments, not as to their soundness or validity, but rather as to what they indicate about Kant's views concerning the cognitive nature of the faculties of sensibility and understanding.

My target is premise (2) of the Intellectualist argument, that the discursive unity granted by synthesis is the fundamental explanation of the unity of intuition. My argument against the primacy of discursive unity proceeds in two steps. In the first step, the argument moves from claims about Kant's conception of the form of pure intuition to a conclusion concerning the independence of this form from any discursive form of unity. If this step in the argument is correct, then premise (2) of the Intellectualist's argument is false.

The second step extends the argument concerning pure intuition to empirical intuition or perception. The purpose of this extension is to foreclose the possible soundness of a weakened Intellectualist argument, which states that discursive unity is necessary only in empirical rather than pure intuition. If my extended argument is successful then even a modified version of premise (2) - namely, one concerned merely with empirical intuition-is false. If both steps succeed, then my arguments demonstrate the generally problematic nature of Intellectualism's stance regarding the unity of intuition. At that point we have a choice: either concede that Kant's view is an incoherent blend of Intellectualist and anti-Intellectualist elements or look for an alternative reading. In the final part of the paper I propose one such alternative reading, which articulates a role for discursive unity in cognition that does not threaten the independent aesthetic unity of intuition.

\section{I Step One: Pure Intuition and Unity}

Kant argues in the Metaphysical Exposition of the Transcendental Aesthetic (A24-25/B39-40, A4 I-42/B47-48) for our non-conceptual or intuitive grasp of space (and mutatis mutandis time). These arguments are worth quoting in full.

Space is not a discursive or, as we say, universal concept of things as such; rather, it is a pure intuition. For, first, we can represent only one space; and when we speak

${ }^{18}$ It is true that the second edition added new headings (such as "Metaphysical Exposition") and changed some of the wording and argument. Nevertheless, the A-edition clearly argues that, for example, space is given as infinite, something that we would not be capable of grasping in a purely conceptual manner independent of intuition (A25). 
of many spaces, we mean by that only parts of one and the same unique space. Nor, second, can these parts precede the one all-encompassing space, as its constituents, as it were (from which it can be assembled); rather, they can be thought only as in it. Space is essentially one; the manifold in it, and hence also the universal concept of spaces as such, rests solely on [our bringing in] limitations. It follows from this that, as far as space is concerned, an a priori intuition of it (i.e., one that is not empirical) underlies all concepts of space. (A24-25/B39; my emphasis)

Space is represented as an infinite given magnitude. Now it is true that every concept must be thought as a representation that is contained in an infinite multitude of different possible representations (as their common characteristic) and hence the concept contains these representations under itself. But no concept, as such, can be thought as containing an infinite multitude of representations within itself. Yet that is how we think space (for all parts of space, ad infinitum, are simultaneous). Therefore the original representation of space is an a priori intuition, not a concept. (B39-40; my emphasis)

The first argument indicates that space is given or presented to the mind as a single whole. Its "parts" are actually limitations. Therefore the representation of space (and time) is "prior" metaphysically to its represented parts, which are dependent upon this whole. It is partially because the representation of space as a whole cannot be built up out of a previous representation of its parts (particular spaces) that Kant considers it as having the status of an a priori representation. ${ }^{19}$

The second argument indicates that our representation of space cannot be fundamentally conceptual, for if it were, we would need to grasp the totality of conceptual parts or "marks" (Merkmale) that constitute its content or intension. ${ }^{20}$ Since this would mean grasping an infinite set of marks (conceptual marks of each individual space or location), it would be impossible for any finite being. Hence, space is not something originally grasped conceptually. ${ }^{21}$

${ }^{19}$ In contrast to this account, compare the accounts of spatial representation in the British empiricists. Locke argues that spatial representation is based on the representation of distance between bodies that we immediately perceive and then join and multiply in order to get an idea of an all-encompassing space (Essay, Book II, chapter iv, sections 3-4; cf. II.xiii.I-I4). Berkeley construes three-dimensional spatial representation as the construction of distance via the association of visual and tactile impressions (Theory of Vision, LX-LXII). Hume construes space as the manner in which colored points are distributed, and extended space as simply a greater distribution of such points (Treatise, Book I, chapter iii, sections 2-5). According to Hume, the representation of depth, in a manner similar to Berkeley's view, is had in virtue of associations between visible and tangible points. All three empiricist theories construe the representation of space as involving construction via additive or other combinatorial operations of the mind.

${ }^{20}$ The primacy of our aesthetic representation of space is, however, compatible with holding that we do in fact have a conceptual grasp of individual spaces (e.g. in analytic geometry). Kant's main point is that our grasp of geometric space, which can involve the arbitrary addition or subtraction of spatial magnitudes, is parasitic upon a non-conceptual grasp of a single unified and all-encompassing space in which such subtraction or addition takes place. For discussion of Kant's theory of concept extension and intension and its significance for the argument of the Metaphysical Exposition, see Friedman, Exact Sciences; Posy, "Immediacy and Reference"; Anderson, "It Adds Up"; Anderson, "Wolffian Paradigm"; Janiak, "Kant's Views on Space and Time."

${ }^{21}$ One might object to this interpretation on the basis that it makes a psychological claim regarding the kinds of concepts that a finite discursive being can apprehend. It might seem better to simply read Kant as asserting that concepts cannot have an infinite number of marks and arguing for the existence of an intuition of space and time from this assertion. Dialectically, however, this seems to put Kant's argument at a disadvantage, for one of his key opponents (Leibniz) did think that concepts 
Recall premise (2) of the Intellectualist's argument. It says that both intuition and judgment have a common source of unity-namely, discursive activity. If this premise were correct then our cognitive grasp of space and time as pure forms of intuition would depend on a discursive form of unification, and thus on the combination of their many parts into a unity. ${ }^{22}$ This is what it means to say that the unity of intuition depends on a discursive unity. ${ }^{23}$ This view entails that our conception of space as an infinite whole would be logically constructed from our grasp of the discrete spaces composing it (whether these spaces are perceived or mathematically grasped). However, this seems to be precisely what Kant denies discursive intellectual activity is able to accomplish. ${ }^{24}$ Kant suggests instead, in the above quotations from the Metaphysical Exposition, that our cognitive grasp of space is holistic. We grasp the whole of space first, and it is in virtue of this that its parts, as limitations of the infinite whole, are conceptually grasped and cognized discursively. ${ }^{25}$

One might attempt to avoid this objection by arguing that it only applies to positions that interpret the forms of intuition as unified by their conceptual content. Such an interpretation, it might be granted, indeed runs afoul of Kant's arguments. However, the suggestion goes, there is an alternative means of construing the dependence of the forms of intuition on the activity of the understanding (or its operation in imagination). According to this alternative, the unity of the forms of intuition depends upon a pre-conceptual synthesis whereby the understanding (specifically, the capacity to judge) acts upon the faculty of sensibility and in doing so provides for the synthetic unification rather than the actual content (propositional or otherwise) of intuition. So it is not the case that the form of (e.g.) space is unified by a conceptual grasp of each of its elements (i.e. individual spaces). Instead, the form is unified according to a rule provided by the understanding in the gathering-together or "comprehension" (Zusammenfassung) of the given "manifold." The most influential contemporary version of this thesis is offered by Béatrice Longuenesse. ${ }^{26}$ She argues that $\$ 26$ of the B-deduction entails a "rereading

could contain an infinite number of marks, even if they could not all be cognized by finite beings; cf. Discourse, §8. This allows Kant to avoid begging the question against Leibniz while allowing him to press the point that if concepts are to play their requisite theoretical role in explaining cognition, which requires that they be susceptible to cognitive processing, then they cannot be of the very same representational kind as those representations that God uses to cognize the world. Along with his arguments considering God as an intuitive intellect, Kant can thus give a substantive reply to the Leibnizian, without simply presuming the denial of the Leibnizian position. Thanks to an anonymous referee for encouraging clarity on this point.

${ }^{22}$ Note that the awareness of space and time as infinite wholes is pure or a priori in nature and therefore not specifically perceptual. I discuss below the significance of this point for the understanding of perception as empirical intuition.

${ }^{23}$ See e.g. McDowell, "Hegel and the Myth," 79. McDowell emphasizes that the unity is a logical one, but this is compatible with describing it as discursive-viz. as the combination of disparate elements into a unified complex whole.

${ }^{24}$ Others have noticed this problem as well. Cf. Falkenstein, Kant's Intuitionism, I39; Messina, "Kant on the Unity of Space"; Onof and Schulting, "Space as Form of Intuition and as Formal Intuition."

${ }^{25}$ For alternative perspective on the holistic nature of the forms of intuition that emphasize phenomenological themes, see Aquila, "Holistic Intuition" and "Infinitude."

${ }^{26}$ Longuenesse, Capacity to Judge, ch. 8. See also Land, "Prescribing Unity" and "Kantian Conceptualism." For further discussion of Longuenesse's reading and the French reception of that reading, particularly by Michel Fichant, see Onof and Schulting, "Space as Form of Intuition and as Formal Intuition." 
of the theory of space and time propounded in the Aesthetic" resulting in a "reinterpretation of the manner in which things are given to us." ${ }^{27}$ The rereading requires that we see the understanding, in the guise of the productive imagination, as synthesizing the manifold of the sensory given in such a way as to make possible the unity of the forms of space and time. ${ }^{28}$

A key text that Longuenesse cites as central to her rereading comes in the dense footnote to $§ 26, \mathrm{~B}$ I 6I. Kant says,

Space, presented as object (as we are actually required to represent it in geometry), contains more than [the] mere form of intuition-viz. it contains also the gatheringtogether [Zusammenfassung] of the manifold given according to the form of sensibility, in an intuitive representation-so that the form of intuition gives us merely a manifold, but formal intuition gives us unity of representation. In the Transcendental Aesthetic I had merely included this unity with sensibility, wanting only to point out that it precedes any concept. But this unity indeed presupposes a synthesis which does not belong to the senses, through which all concepts of space and time first become possible. For through this unity (inasmuch as understanding determines sensibility) space or time are first given as intuitions, and hence the unity of this intuition belongs a priori to space and time, and not to the concept of understanding (see §24). (BI6In)

According to Longuenesse, the footnote demonstrates Kant's reinterpretation of his discussion of a priori intuition in the Transcendental Aesthetic in order to bring it in line with the argument of the Deduction. Her claim is that via an act of the understanding on the faculty of sensibility, which Kant terms a "figurative" synthesis or "synthesis speciosa," the pure intuitions of space and time are generated. This "determination" of sensibility by the understanding, which generates the pure intuitions of space and time, is nevertheless importantly pre-conceptual, and thus does not entail (so Longuenesse argues) any conflict with the account Kant gives in the Aesthetic of the intuitive nature of space and time. ${ }^{29}$ This is why, says Longuenesse, Kant can claim in the note quoted above both that the unity of intuition presupposes a synthesis that "does not belong to the senses" while also claiming that the unity of intuition belongs to space and time and "not to the concept of the understanding."

The problem with the rereading Longuenesse proposes-and, more generally, with any proposal that attempts to avoid my objection via an appeal to preconceptual synthesis-is that it does not fit with Kant's general view of the nature of our finite intellectual activity. According to Kant, intellectual activity in finite

\footnotetext{
${ }^{27}$ Longuenesse, Capacity to Judge, 208-9, 2 I3.

${ }^{28}$ There is some debate as to whether the imagination should be understood as part of the understanding's activity or part of sensibility's receptivity. For example, Hanna ("Kant and Nonconceptual Content," 249) argues for sensibility as itself being spontaneous in virtue of having a productive imagination. However, Kant is quite explicit in the B-edition of the Critique that the productive imagination is merely the understanding under another name ( $\mathrm{B}_{1} 62$, note). One advantage of my argument is that it avoids the issue of whether the imagination is part of the understanding or sensibility. Instead, my argument depends only on the idea that the activity characteristic of human cognitive activity, whether imaginative or explicitly intellectual, cannot bring about the requisite unity of the forms of intuition, given Kant's characterization of those forms in the Metaphysical Expositions and his characterization of human cognitive activity as structured via a dependence relation of whole on part. For this reason, I will continue to talk interchangeably of the understanding or its activity via the imagination, since the same fundamental form of structuring activity takes place in both cases.
}

${ }^{29} \mathrm{Cf}$. Longuenesse, Capacity to Judge, 2 I 6. 
beings such as ourselves always proceeds from part to whole (CJ 5:407; cf. B72; CJ 5:25I-54). These parts are run through, gathered together, and related to one another in the process Kant terms "synthesis" (A77/BI03; A99). Hence, any spontaneous activity on the part of the intellect, whether it be conceptual application in a judgment, or implicit rule-governed construction (such as in the careful imagination of complex shape), the nature of the activity must proceed via a movement from part to part, out of which a representational whole may be fashioned. Note that this is completely compatible with Kant's claim in the later footnote to BI62 that one and the same understanding can perform both an imaginative and a conceptual synthesis. But since it is the very same understanding at work in both cases, I take it that the synthesis carried out in each case will manifest this part-to-whole structure, insofar as it is a fundamental characteristic of the understanding to act in such a manner. ${ }^{30}$ Thus, if a representation has a structure in which the parts depend on the whole rather than a structure in which the whole is dependent on its parts, that representation cannot be a product of intellectual activity, but must rather be given in sensibility independently of any such activity. ${ }^{3 \text { I }}$

How then should we understand the footnote? If space and time, as pure forms of intuition, have an independent unity, it cannot be the case that the unity of intuition that Kant talks of in the footnote is in fact the aesthetic unity of the pure forms. Instead, Kant is speaking of the unity of space and time as mathematically describable objects, such as the geometric space represented by Euclidean geometry. Kant signals this, I claim, at the start of the passage, where he explicitly references space represented as an object "as we are required to represent it in geometry.” As I argue in $\$ 3$ below, the conditions for representing something as an object of knowledge are different from, and much more demanding than, the conditions necessary for objective representation. So Kant can consistently hold that the unity of the representations of the pure forms of intuition-space and time-is independent of any synthesis, while acknowledging that the representation of these entities as objects, as we do in mathematics, requires a pre-conceptual synthesis carried out by the imagination. ${ }^{32}$

Kant's picture of finite intellectual activity as discursive thus has significant ramifications for his understanding of our grasp of space and time as infinite

${ }^{30} \mathrm{Cf}$. note 28 above. Thanks to an anonymous referee for emphasizing the importance of addressing this issue.

${ }^{3}$ The view presented here is in stark contrast to the discussion of synthesis and representation in Dickerson, Kant on Representation and Objectivity. Dickerson there construes synthesis as essentially holistic. This characterization is guided by what he takes to be Kant's endorsement of the priority of whole judgments over their conceptual parts, and of this priority view as a solution to the problem of the unity of the proposition-see esp. 5I-52, I I9-22, I 3 I-48. Though I agree that Kant is concerned with issues of propositional (in Kant's terms, "judgmental") unity, and that he does endorse some form of the priority of judgment over its conceptual parts, I do not see this as requiring or sanctioning a view of intellectual synthesis as holistic. There is an important sense in which a discursive subject's consciousness is holistic, but the intellectual activity of synthesis is not. For further discussion of Dickerson's view, with particular emphasis on the issue of self-consciousness, see Rosefeldt, "Review."

${ }^{32}$ Kant also denies that the understanding generates, in any way, the forms of intuition in a letter to Herz in May of I789 ( I I:49-5 I). For further discussion of the footnote, see Onof and Schulting, "Space as Form of Intuition and as Formal Intuition." 
singular wholes. Kant's point in the third and fourth arguments of the Metaphysical Exposition is that no finite intellect could grasp the extent and nature of space and time as infinite wholes via a movement from part to whole. The appeal to a preconceptual synthesis does not avoid this objection, for it presumes that the unity of the forms of intuition is also something dependent upon intellectual activity, and thus must involve the discursive (even though not conceptual) running through and gathering together of a given multiplicity (presumably of different locations or moments) into a combined whole. ${ }^{33}$

Kant's arguments in the Expositions of space and time require that the fundamental basis of our representation of space and time does not proceed from a grasp of the multiplicity of features of an intuited particular to the whole that has those features. Instead the form of pure intuition constitutes a representational whole that is prior to that of its component parts (cf. CJ 5:407-8, 409). ${ }^{34}$

Hence, Kant's position is that the pure intuitions of space and time possess a unity wholly different from that given by the discursive unity of the understanding (whether it be in conceptual judgment or the intellectual cum imaginative synthesis of intuited objects more generally). ${ }^{35}$ The unity of aesthetic representation-characterized by the forms of space and time- has a structure in which the representational parts depend on the whole. The unity of discursive representation-representation where the activity of the understanding is involved-has a structure in which the representational whole depends on its parts. ${ }^{36}$

Once we see that intellectual activity, including synthesis, must operate in this broadly discursive manner of running through and gathering together a manifold, it becomes very difficult to understand how any such rereading of Kant's argument

\footnotetext{
${ }^{33}$ Note that this need not commit Kant to denying that we can have the concept $<$ infinity $>$. This is because <infinity $>$ need not itself have an infinite number of parts or marks that require grasping. The infinite extent of the natural numbers, for example, is not grasped via a grasp of each member of the series (i.e. via a grasp of the extension of the series). Instead, it is grasped by means of a recursive definition using the notion of a successor.

${ }^{34}$ Kant's extremely brief discussion of the "synopsis of the senses" may be indicative of the special nature of our intuitive grasp of things; see A94, A97. Heidegger makes much of this notion as well, especially in the discussion of his notion of syndosis; see Heidegger, Phenomenological Interpretation, 95-96, I80-88.

${ }^{35}$ Kant's argument here is directed very much against the Leibnizian view that all representation is purely intellectual. The Leibnizian explains the perception of space and spatial relations as a product of the intellectual confusion inherent in the finite perceiver's conceptual representation of a fundamental monadic order. Kant thinks that this would result in a concept with infinite content (i.e. different conceptual marks for each different space). If we were to attempt to grasp such a representation discursively, we would be faced with the infinite task of running though representations of the infinite number of spaces and times that constitute the wholes of space and time (A25/B39-40, $\mathrm{A}_{32}$ ) B 47-48; CJ 5:409). This is a task Kant thinks could never be accomplished by a finite mind; cf. note 2 I above. For further discussion see Adams, Leibniz ch. 9; Janiak, "Kant's Views on Space and Time."

${ }^{36}$ One might wonder what explains, for Kant, our capacity for a holistic cognition in intuition. It is not clear that he has an answer to this question. However, it is not clear that Kant needs an answer to this question. All Kant needs is a relatively clearly defined notion of conceptual or intellectual activity (which he does have) with which he can contrast the kind of cognitive capacity needed to account for the awareness of space and time. If Kant's previous arguments in the Metaphysical Exposition for the a priori awareness of space and time are correct, then he can argue that we must have whatever capacity is required to explain this awareness. So the further explanation as to what explains this capacity is not a necessary part of Kant's argument.
} 
in the Transcendental Aesthetic concerning the intuition of space and time could cohere with his broader commitments. ${ }^{37}$ Such a rereading threatens the success of Kant's argument in the Aesthetic as a whole, for it threatens his argument to establish space and time as forms of intuition and thus as transcendentally ideal. It therefore seems implausible that Kant's argument in the Deduction requires the rejection of arguments central to a fundamental tenet of his critical philosophynamely, that space and time are forms of subjectivity and not things in themselves. ${ }^{38}$

Moreover, Kant maintains his views concerning both the nature of our discursive intellect and the holistic character of intuition in later published works. For example, the third Critique, written a decade later, also expresses views concerning the holistic character of intuition and the partial character of discursive thought (CJ $\$ 26-27,76-77)$. This suggests that the arguments made in the Aesthetic

${ }^{37}$ Griffith ("Perception and the Categories") fails to address this point in a discussion of issues surrounding a conceptualist interpretation of Kant. He says, "The only obvious sense in which the representations of space and time are nonconceptual (according to the Aesthetic) is the sense in which those representations are themselves not concepts" (24). But the passages above clearly show that this trivial claim is not the only thing to be said about the argument of the Aesthetic. Indeed, failure to appreciate the distinctive nature and unity of the intuitions of space and time means a failure to appreciate the problem which Kant sets for himself in the Analytic-viz. how it is that discursive thought can grasp a non-discursively disclosed given.

${ }^{38}$ Longuenesse comes closest to answering my challenge in her 2005 discussion of the imagination's role in the representation of space and time. She says, "[W] hen Kant says that what is thus isolated [i.e. time and space] is a 'being of imagination,' in my view he can only mean that it is the imagination which makes space and time present to us: although it does not produce them by a process of Dichten or Zusammensetzen (as it does for imaginary representations and geometrical figures), it grounds on them all its Dichtungen and Zusammensetzungen" (Standpoint, 75). But the fact that the representations of space and time, in their unity of form, do not depend on a composition or "a process of Zusammensetzen" does not mean that their unity is provided in a way that does not require moving from part to whole. As I argued in the text above, it is a general feature of our intellectual activity that it must proceed from part to whole, and this is equally true of other forms of activity (e.g. gathering-together or "comprehension" [Zusammenfassung] as it is of composition; cf. CJ 5:25 I-52). Longuenesse assumes, in my view without justification, that it is only conceptual composition (Zusammensetzung) that is at issue. Relatedly, Friedman ("Spatial Intuition") suggests that Kant's account of our representation of an all-encompassing (allbefassende) space (and similarly time) requires that the form of space be comprehended (zusammengefasst) in a pre-conceptual act of the understanding (cf. Longuenesse, Capacity to Judge, 2I 5-I6). However, I think it is an error to identify the unity of all-encompassing space, qua form of intuition, with an intellectual act for precisely the reasons I have set out above. A further point in favor of my separating the "allbefassende" space from a "zusammengefasst" space is Kant's discussion of the representation of spatial magnitudes in $\$ 26$ of the third Critique. There he argues,

To take up a quantum in the imagination intuitively, in order to be able to use it as a measure or a unit for the estimation of magnitude by means of numbers, involves two actions of this faculty: apprehension [Auffassung] (apprehensio) and comprehension [Zusammenfassung] (comprehensio aesthetica). There is no difficulty with apprehension, because it can go on to infinity; but comprehension becomes ever more difficult the further apprehension advances, and soon reaches its maximum, namely the aesthetically greatest basic measure for the estimation of magnitude. For when apprehension has gone so far that the partial representations of the intuition of the senses that were apprehended first already begin to fade in the imagination as the latter proceeds on to the apprehension of further ones, then it loses on one side as much as it gains on the other, and there is in the comprehension a greatest point beyond which it cannot go $(5: 25 \mathrm{I}-52)$.

It is altogether unclear why comprehension (Zusammenfassung) would have such difficulty with infinite magnitudes if, as per Friedman's suggestion, the all-encompassing unity of the form of space as an infinitely given quantity (B39-40) were due to an act of comprehension in the productive imagination. 
cannot be simply reinterpreted in light of arguments presented (or thought to be presented) in subsequent parts of the first Critique, for the Intellectualist rereading of the Aesthetic would require not just a rejection of Kant's arguments as put forward there, but also a rejection of positions he held consistently over the span of the critical period.

This ends the first step of the argument. If this argument is correct, then the Intellectualist interpretation of the argument Kant puts forward at BI60-6I is in deep tension with Kant's position in the Aesthetic, for it cannot be the case that the unity of the forms of intuition itself depends on discursive activity, preconceptual or otherwise.

\subsection{Step Two: Perception and Unity}

I have argued that the pure forms of intuition must have their own form of unity independent of anything offered by the discursive activity of the intellect. Therefore premise (2) of the Intellectualist argument is false. Intuitions and judgments do not have a common source of unity in the nature of discursive activity. Instead, the unity of intuition is given rather than made.

However, one might object that this argument does not yet demonstrate that impure intuition-i.e. empirical intuition-is independent of intellectual activity. Perhaps intellectual activity is required for perception in a way in which it is not required for a priori intuition. In this case Intellectualism argues for a revised, limited version of premise (2):

\section{(2 ): Both empirical intuition and judgment have a common source of unity-name-} ly, discursive activity.

Restricting the argument of Intellectualism to merely empirical intuition has the advantage of avoiding the considerations militating against its application to the forms of intuition. Moreover, with regard to mereological relationships, Kant seems committed to understanding empirical intuition differently than pure intuition. He says, "I call an extensive magnitude that in which the representation of the parts makes possible the representation of the whole" (AI62/B203). Since Kant claims all intuitions are extensive magnitudes (AI62/B20I), he would seem to be clearly committed to at least the restricted version of premise (2) and thus the restricted version of Intellectualism.

However, there are problems with the restricted version of the argument. First, Kant's argument in the Axioms of Intuition, from which the above quote is taken, applies only to determinate appearances, in contrast to his introduction of the notion of an appearance as the indeterminate object of an empirical intuition $\left(\mathrm{A}_{2} \mathrm{O} / \mathrm{B}_{34}\right) .{ }^{39}$ This would suggest that we do indeed have intuition prior to any determination (where the latter presumably occurs via a synthesis by the understanding) and thus, contra $\left(2^{\prime}\right)$, that empirical intuition exists independently of any unification offered by the understanding.

\footnotetext{
${ }^{39}$ Sutherland ("Kant's Axioms") offers a similar diagnosis of the relation between the Aesthetic and the Principles. To the extent that we differ it is with respect to an understanding of this notion of determination. I discuss this issue of determination further with respect to Kant's idea of "combination" (Verbindung) in $\$ 3$ below.
} 
Second, premise ( $\left.2^{\prime}\right)$ appears somewhat ad hoc. Kant presents the conditions for the unity of the forms of intuition in a way that requires continuity of structure between the forms of intuition and particular empirical intuitions. After all, Kant arrives at the pure forms of intuition by abstracting from all the empirical characteristics of a given empirical intuition (A2O-2 I/B34-35). This implies that in any given empirical intuition, the purely formal characteristics of intuition are also present. So once the unity of the forms of intuition has been conceded, it is no longer clear why all intuitions do not possess a form of unity independent of the understanding. If Intellectualism is going to object that empirical intuition stands in special need of unification in the relevant sense, then the burden is on Intellectualism to tell us why unity is required at the point of empirical intuition rather than pure intuition.

A third worry concerns the dialectical motivation for endorsing Intellectualism. Part of the attraction of Intellectualism lies in its promise of making sense of the argument of the B-Deduction. According to Intellectualism, fulfilling this promise requires the demonstration of the dependence of the forms of intuition (i.e. space and time themselves) on synthesis. This is presumed to be the argument of $\S 26.4^{\circ}$ According to Intellectualism, if the representations of space and time themselves depend on the categories, then since anything that appears in space and time will be subject to the same fundamental conditions for representation as space and time themselves, such appearances will necessarily be subject to the categories. ${ }^{4}{ }^{\mathrm{I}}$ But once the claim that the unity of the pure forms of intuition is fundamentally discursive has been given up, the Intellectualist's proposed interpretation of the role that the forms of space and time play in the Deduction no longer holds. For if I am right, then the original aesthetic unity of space and time cannot depend on synthesis, categorical or otherwise. So Intellectualism no longer has the resources to provide an interpretation of the argument of $\$ 26$ that could account for the supposed necessity with which the categories apply to objects of experience, and thus lacks a crucial motivating element. ${ }^{42}$

We are thus left in a rather difficult position. Intellectualism is by far one of the most widespread and well-developed interpretations of Kant's critical philosophy generally, and of the argument Transcendental Deduction in particular. If the two steps of the argument I laid out above are correct, then either Kant incoherently endorses both Intellectualist and anti-Intellectualist claims in his critical philosophy, or Intellectualism is, despite its other attractions, a deeply problematic interpretive position, which may need to be abandoned.

${ }^{4 \circ} \mathrm{Cf}$. Longuenesse, Capacity to Judge; Pereboom, "Kant's Deductions."

${ }^{4}$ For an especially clear discussion of this point, see Griffith, "Perception and the Categories," $\S$ IO. Interpretations such as Longuenesse's (which advocate a pre-conceptual synthesis that accounts for representation of space and time) will be more complicated in the story they tell concerning the necessity of the categories, but the general strategy and importance of $\$ 26$ of the B-Deduction in that interpretive strategy is the same.

${ }^{42} \mathrm{This}$ is true even if we admit that Kant seems to require that the categories be in some way necessary for the representation of empirical objects. Certainly that seems to be the thrust of Kant's argument in the B-Deduction (cf. $\mathrm{B}_{I} 43, \mathrm{BI}_{\mathrm{I}} \mathrm{I}, \mathrm{B}_{1} 65$ ). The point I make above against Intellectualism is simply that the most obvious strategy for achieving this conclusion-according to which the pure forms of intuition depend for their generation on the activity of the intellect—is vitiated once Intellectualism gives up premise (2). 
To be sure, conviction concerning this point is hard to come by in the absence of an alternative positive account of the argument of the Deduction. Kant's emphasis there on the unifying role of categorical synthesis gives the impression that the unity of intuition is ineluctably linked to the discursive unity provided by the categories (cf. BI43-44, BI 52, BI60-6I). This issue demands further discussion. But first, in the next subsection, I discuss a series of objections that may arise in reference to Kant's claim concerning our having intuitions of infinite wholes. I then go on, in $\S 3$, to provide a sketch of how we might understand the relation between the aesthetic unity of intuition and a distinct notion of unity-namely, discursive unity - that I take to be the topic of the Deduction. Finally, I show that the controversial argument at $\mathrm{B}_{160-62}$ (discussed above), is compatible with this alternative reading.

\subsection{An Objection: Totality and Unity}

One might object that my argument concerning the primacy of the intuitive and holistic representation of space commits Kant to the view that we have an actual intuition of the infinite totality of space (and correspondingly time). This would be at least prima facie problematic for three reasons. ${ }^{43}$ First, it seems cognitively implausible, at least for finite minds. Second, it is incompatible with Kant's view that we cannot represent an actual infinity (B40, A432/B460). Third, it also seems incompatible with the receptive nature of sensibility, since receptivity requires affection of the senses, and it is implausible that an infinite whole affects our senses. Let us take these in turn.

First, it certainly seems true that we do not perceptually intuit space as an infinitely large object, since this is both phenomenologically and cognitively implausible. ${ }^{44}$ Indeed, it is difficult even to conceive of the phenomenological character of being presented with an infinitely large object. But it is not necessary (or proper) to tie pure intuition to perception, for the third and fourth arguments of the Metaphysical Exposition do not entail this absurd claim. Instead, all they phenomenologically require is that any perceptual experience of a space, or of something shaped and located in space, requires a representation of that space as merely a limitation of a larger whole. So for any experience of a bounded region, that experience is made possible in virtue of a representation of a larger region that encompasses the bounded one, and so on. Moreover, this way of conceiving of the perceptual presentation of particular spaces is sufficiently problematic for empiricist views, which must argue that space represented as infinite in magnitude depends on a construction out of particular perceived spaces or spatial points rather than being given as a condition for their representation (e.g. Locke, Essay, II.xiii.4, I68). Hence interpreting Kant's claim in the way I have suggested still leaves it with bite against his empiricist opponents.

This brings us to the second problem, that the holistic grasp of space as an infinite given magnitude (B39-40) requires that we are able to cognize an actual infinity, which is something Kant denies. The magnitude of a thing must be thought

${ }^{43}$ Thanks to Thomas Land for discussion of these issues.

${ }^{44}$ See Shabel, "Reflections on Space," 52 for expression of a similar worry. 
through a synthesis of its parts, and an infinitely large thing requires an infinite synthesis (A433/B46I; cf. AI62-63/B203). The representation of an infinite magnitude would therefore require completion of an infinite task-namely, the synthesis or combination of all the members of the infinite totality-something that, according to Kant, is impossible. ${ }^{45}$

The important thing to note in reply to this objection is that, for Kant, there are two different ways in which a whole can be represented, and only one of those ways is problematic. There is a difference between the conceptual representation of space as an infinite magnitude, which would require precisely the problematic form of part-whole discursive cognition that Kant highlights, and the intuitive representation of the whole, which does not require the problematic representation of it through a representation of its parts. ${ }^{46}$

Kant explicitly characterizes space as a totum, that is, as a whole that is prior (in the sense of grounding) to its parts. ${ }^{47}$

One should actually not call space a compositum but rather a totum, because the parts of space are only possible through the whole, rather than the whole being made possible through the parts. (A438/B466; cf. R 3789, I7:293; R 5299, I8:I47)

The status of space as a whole or totum in this sense means it does not fall prey to the kind of objection Kant raises against our cognition of the natural world as a whole in the mathematical Antinomies. There the issue concerns a "totum syntheticum," or synthetic whole that is constructed from its parts. Henry Allison puts the issue this way:

$[\mathrm{T}]$ he problem is that the rule or procedure for thinking a totum syntheticum [i.e. a whole which is not prior to its parts] clashes with the one for thinking an infinite quantity. The former demands precisely what the latter precludes, namely, completability (at least in principle)..$^{8}$

So the problem Kant raises for the grasp of infinite magnitudes such as the extent of the natural world is a problem only for a certain kind of whole-one that depends on its parts. Since space and time, as forms of intuition, do not have this feature, they are exempt from the worry. This is not to justify Kant's claim that space and time are indeed such wholes, but it does show that his exposition of space and time as infinite given magnitudes need not conflict with his discussion of problems related to the discursive cognition of infinite wholes in the Antinomies.

Finally, there is the issue of receptivity and the forms of intuition. Kant is very clear that space and time, as forms of intuition, are ideal and so do not disclose

${ }^{45}$ See Bennett, Kant's Dialectic, I 20-2 I.

${ }^{46} \mathrm{It}$ is important that one keep in mind here the distinction between a conceptual representation whose extension is infinite and a conceptual representation whose content or intension is infinite. Kant's worry is specifically directed against conceptual representation that involves an infinitely complex intension, or series of conceptual marks. Conceptual representation by finite minds is compatible with a concept's applying to an infinite number of things or being a mark in an infinite number of subordinate concepts. See the sources cited in note 20 above.

${ }^{47}$ For contemporary discussion of the notion of grounding in metaphysics, see Schaffer, "On What Grounds What" and "Monism." For discussion of the relationship between metaphysical notions of grounding and Kant's epistemology, see Smit, "Apriority."

${ }^{48}$ Idealism, 370. Bell ("Propositional Unity") also highlights the importance of distinguishing in Kant different notions of the part/whole relation. 
the natures of any objects as they are themselves. But the claim that we have a holistic cognitive grasp of the basic characteristics of space and time suggests that something is indeed given to the subject. Such givenness implies a modification of the subject's receptivity, which seemingly contradicts the claim that the forms of intuition are ideal.

I suggest the following resolution. First, characterizing intuition as holistic and using this to explain our grasp of space and time is completely compatible with the idea that space and time are forms of intuition, for it helps explain how these forms are intelligible as ways of being receptive to objects. The first (space) is the way of being receptive to objects distinct from the subject; the second (time) is the way of being receptive to the subject's own modifications. Since space and time are ways in which a subject is receptive, they need not be considered as independent entities capable of affecting the subject herself. So they may be given as the subject matter of cognition without requiring that they be the result of a modification of the subject.

Second, the claim that the intuition of space is of an infinite whole is compatible with that given whole having a form of being that is entirely dependent on the subject. ${ }^{49}$ So there is nothing about the claim that space may be given to the subject that is incompatible with the ultimate subject-dependence of the forms of intuition.

\section{D I S C U R S I V E U N I T Y}

I have thus far given a largely negative argument concerning the nature of the unity of intuition. This "aesthetic unity," as I have called it, is had both by the pure intuitions of time and space and individual empirical intuitions, insofar as they possess spatial and temporal form, and cannot be accounted for by intellectual synthesis. Kant claims further that intuition and conceptual judgment are both forms of objective representation $\left(\mathrm{A}_{3} 20 / \mathrm{B}_{376-77)}\right.$. So if what I have argued thus far is correct, then intuition is a form of objective representation independent of any form of intellectual (or imaginative) synthesis.

This conclusion raises an immediate problem. Kant is clearly committed to the understanding's having an integral role in synthesizing intuitive representations, and in particular, empirical representations. But if, as I have argued, intuition has its own form of unity, it is not clear what is left for categorical synthesis to do. What is needed is an account of how this second form of unity-namely, discursive unity-interacts with aesthetic unity and what this means for understanding the argument of the Deduction. In what follows I articulate the relationship between aesthetic and discursive unity and show why a discursive unity of representation is necessary for empirical cognition, even if we grant that intuition alone

${ }^{49}$ Exactly which subject, the empirical or the transcendental, constitutes the ground for this dependence is perhaps more difficult to say. However, since the empirical subject is herself in space, it seems more promising to identify the subjectivity of intuition with dependence upon the transcendental subject. For a phenomenologically inspired interpretation of the nature of space, see Heidegger, Phenomenological Interpretation. For a related interpretation that construes space and time as special sorts of intentional objects, see Aquila, "Infinitude." For criticism of the idea that space and time could be primitively "given" to the subject, see Messina, "Kant on the Unity of Space." 
counts as a form of objective representation..$^{\circ} \mathrm{I}$ examine various passages from the B-Deduction, and especially from $\$ 26$, where Kant explicitly claims that perception requires categorical synthesis. I show how these texts are compatible with intuition's possession of an independent aesthetic unity, and thus its status as an objective representation independent of any synthesis. Since these texts are, of Kant's writings, among those most suggestive of Intellectualism, my hope is that their discussion will go some way toward vindicating a Sensibilist reading of the Deduction.

\section{I Discursive Unity and Combination}

We can begin to see the special role that the understanding plays in cognition by noting a key difference between the consciousness marked by the occurrence of an intuition, and the consciousness of that which is given in such an occurrence as combined (particularly as combined with other intuitions). Kant explicitly discusses the possibility of the former, episodic, form of consciousness in a 1789 letter to Herz. He says,
[A]ll sense data for a possible cognition would never, without those conditions [exemplified by the a priori categories], represent objects. They would not even reach that unity of consciousness that is necessary for knowledge of myself (as object of inner sense). I would not even be able to know that I have sense data; consequently for me, as a knowing being, they would be absolutely nothing. They could still (if I imagine myself to be an animal) carry on their play in an orderly fashion, as representations connected according to empirical laws of association, and thus even have an influence on my feeling and desire, without my being aware of them (assuming that I am even conscious of each individual representation, but not of their relation to the unity of representation of their object, by means of the synthetic unity of their apperception). (C I I:52; my emphasis)

The key point in this text is that Kant allows for the possibility that a nonrational animal, lacking a faculty of understanding capable of synthesizing its representations, could still have a sort of episodic consciousness in which individual representational states nevertheless count as states of awareness. The kind of awareness here is extremely limited, encompassing only the immediate content of the representation. As Kant points out in the above passage, such states could causally interact with one another, and there may be other associative mechanisms governing their interaction as well, but there is no awareness, on the part of the subject having such states, that it is having them. We can presumably allow the possibility that such states are phenomenally conscious (there is something it is like to have them), and that a train of such associatively connected states provides a limited sort of viewpoint on the world, but Kant is clear in the passage above that no unitary and self-aware subject arises from a collection of such states.

50'Empirical cognition' is a translation of Kant's 'empirische Erkenntnis.' We should not confuse it with knowledge, understood as a propositional attitude. Kant has a separate term for that: 'Wissen.' As I understand the phrase 'empirical cognition,' it denotes thoughts with empirical content, perhaps even true content (though this is less clear, since Kant may allow for false cognition; cf. A58/B83). See also the discussion in note 54 below. 
One may wonder whether such representational states (in which anything more than this fragmented episodic consciousness is possible) really deserve to be called intuitions. While I will not discuss the matter here, elsewhere I have argued that serious difficulties result for Kant if we take him as denying such episodic unsynthesized representations the status of intuitions. ${ }^{5 \text { I }}$ Moreover, if the arguments of $\$ 2$ above are correct, then we have good reason to believe Kant recognizes not only the possibility of unsynthesized intuition, but also its actuality. However, there is a further worry. Even if one grants me that intuitions may occur apart from the capacity for any unitary form of consciousness, Kant nevertheless explicitly states at the beginning of the passage above that such representations could never represent objects. This problem is mitigated by recognizing an important ambiguity. Kant could be claiming here either that such uncombined representations lack any objective significance whatsoever, or merely that though they are representations of objects (or features thereof), they do not represent them as objects. ${ }^{52}$ It is for this latter reading that I shall argue.

Hence, according to my preferred reading, intuitive representationsspecifically, empirical intuitions - uncombined by any act of synthesis, nevertheless provide episodic consciousness of some sensory quality of an object (e.g. its color, shape, location), but do not represent that quality in any way such that the subject is conscious of it as inhering in or otherwise predicated of an object. ${ }^{53}$ Intuition is thus a form of objective representation, but it is not yet a representation of an object. In Kant's terms, it is not yet an 'empirical cognition.' ${ }^{54}$ For that, combination is necessary. We turn now to why Kant thinks this is so.

Kant is very clear, at the start of the B-Deduction ( I $_{5}$ ), that all combination comes from the understanding and can never be given in an intuition $\left(\mathrm{B}_{\mathrm{I}} 29-30\right) .55$

${ }^{5}$ Cf. McLear, "Kant on Animal Consciousness" for discussion of this, as well as further discussion of the distinct senses in which such beings might enjoy consciousness.

${ }^{52}$ Cf. Allais, "Non-Conceptual Content," 405.

${ }^{53}$ Cf. Allais, "Non-Conceptual Content" for exposition of a similar view regarding the content of intuition.

${ }^{54}$ Though 'cognition' has become the standard translation of 'Erkenntnis,' and is certainly an improvement over Kemp Smith's translation of it as 'knowledge,' it does not sit especially well with my characterization of intuition as itself a form of objective representation. The worry is that, according to my view, intuition itself might seem to be cognition, and thus in violation of Kant's many statements that cognition requires a cooperation between sensibility and understanding. Against readings of Erkenntnis as a kind of knowledge, it is important to keep in mind Kant's occasional turns of phrase involving ‘false cognition' (falsche Erkenntnis) (A58/B83, A709/B737). In any case, if 'cognition' is to be the favored translation of 'Erkenntnis,' we should avoid jumping to a conclusion, driven merely by choice of language, that an Erkenntnis is the most basic form of mind-world relation. Kant's actual philosophical views should be established independently of any single point of translation. In light of this, I think it is important to distinguish between 'cognition' in Kant's sense and a mental state's being cognitive or cognitively significant. The latter are states in which there is mind-world rapport and not simply causal contact. But the cognitive status of such states is compatible with their being impoverished in a variety of ways, such that it is only through the activity of the understanding that such a mental state comes to stand as a full-blown "cognition" in Kant's sense. For a prominent alternative translation of 'Erkenntnis' as 'reference,' see George, "Kant's Sensationism."

${ }_{55}^{5}$ I should note here that I understand Kant's notion of "combination" (Verbindung) as synonymous with "synthesis." This is justified by Kant's tendency to characterize all acts of synthesis as acts of combination (e.g. A77/BIO2, AI62/B20I, note). It is also justified by his denial, noted above, that combination cannot be given, and that it must always be brought about via an act of the understanding. 
Here he is simply agreeing with a widespread assumption, common among both moderns and scholastics, that only the manifest features of an individual are presented in sensibility, while the manner in which those features are related to one another in one individual is not. As Kant puts it in the Inaugural Dissertation,

[O]bjects do not strike the senses in virtue of their form or aspect. Accordingly, if the various factors in an object which affect the senses are to coalesce into some representational whole there is needed an internal principle in the mind, in virtue of which those various factors may be clothed with a certain aspect, in accordance with stable and innate laws. (ID 2:292-93)

Though it is, of course, controversial as to how exactly the Dissertation relates to Kant's position in the critical period, this view seems remarkably in sync with the assumptions of the B-Deduction.

Moreover, Kant is actually fairly clear, at two different places in the B-Deduction, that it is the awareness of relations holding between elements given in an intuition with which he is primarily concerned, rather than the having of an intuition itself.

We must now explain how it is possible, through categories, to cognize a priori whatever objects may come before our senses-to so cognize them as regards not the form of their intuition, but the laws of their combination - and hence, as it were, to prescribe laws to nature, and even to make nature possible. (BI 59-60; my emphasis)

Therefore all possible perceptions, and hence also everything whatever that can reach empirical consciousness, i.e., all appearances of nature, must in regard to their combination be subject to the categories. Nature (regarded merely as nature as such) depends (as natura formaliter spectata) on the categories as the original basis of its necessary law-governedness. (BI64-65; my emphasis)

In both of these passages Kant specifies that what is subject to the categories is everything that can reach empirical consciousness with regard to its combination (ihrer Verbindung nach). But this position is clearly compatible with the position regarding intuition that I discussed above. ${ }^{56}$ The difference is one between a primitive episodic consciousness of the qualities of objects, arrayed in space and over time, and the more sophisticated representation of complexes, such as a temporally persisting spatial array whose different qualities are all represented as grounded in one individual. ${ }^{57}$

Keeping in mind the fact that it is this consciousness of combination that Kant is concerned with in the Deduction helps clarify some otherwise extremely Intellectualist-sounding passages from $§ 26$. For example, Kant says,

First and foremost I note that by the synthesis of apprehension I understand the composition of the manifold in an empirical intuition [die Zusammensetzung des Mannigfaltigen in einer empirischen Anschauung], through which perception, i.e. the empirical consciousness of the same [derselben] (as appearance) first becomes possible. (BI60)

${ }^{56}$ For a similar reading of these passages, see Tolley, "The NonConceptuality of the Content of Intuitions," $\$ 6$.

${ }^{57}$ I should emphasize here that I am construing primitive episodic consciousness, despite its simple structure, as itself a form of objective representation. This is in sharp contrast to positions where such episodic consciousness is of purely subjective qualia, which at best causally co-vary with mind-independent entities; cf. George, "Kant's Sensationism"; Pereboom, "Kant on Intentionality." 
Further on Kant reiterates this claim in connection with the categories.

It follows that all synthesis, through which perception itself becomes possible, stands under the categories, and since experience [Erfahrung] is cognition through connected [verknüpfte] perceptions, the categories are thereby the conditions of the possibility of experience, and are thus also valid a priori for all objects of experience. (BI6I)

These passages apparently indicate that perception itself-namely, the apprehension of an appearance-depends on synthesis in general and the categories in particular. This would seem to indicate the correctness of the Intellectualist interpretation and thereby threaten my proposal concerning the independence of aesthetic unity. But the important point to notice about these passages is that Kant is concerned with our consciousness of the composition of the manifold of an intuition, not the consciousness marked by the occurrence of the intuition itself. So the notion of "perception" (Wahrnehmung) that Kant has in mind is the apprehension in consciousness of what is given in intuition (i.e. the "manifold") as a single unitary, though complex, representation. Thus when Kant says that a synthesis of apprehension is necessary for perception, and that, more generally, categorical synthesis is necessary for perception, what he means is that categorical synthesis is necessary for the empirical consciousness, not of what is intuited, but rather of what is intuited as combined into a complex whole.

Once again, we can accept Kant's claim here without going so far as to agree with Intellectualism that there is no objective representation without combination. Kant's claim that the consciousness of combination requires synthesis is compatible with a subject's being capable of enjoying a merely episodic consciousness, where such episodes consist of occurrences of unsynthesized intuitions.

If this is correct, then Kant's argument demonstrating the legitimacy of the categories is not meant to show that conscious sensory apprehension of the world is made possible by the categories, but rather only that the apprehension of what is given in intuition as combined -what Kant terms "perception"-is made possible by the categories and the syntheses they effect. The categories make possible the having of unitary but nevertheless complex representations, which govern our grasp of objects as complex entities. But the categories are not required for establishing a cognitive connection with the world in general. That this is nevertheless a substantive claim can be seen when we contrast Kant's view with that of Locke, to which we will now turn.

\subsection{Locke and Kant on Complex Representation}

According to Locke, at the basis of all our ideas or representations of things are socalled "simple" ideas, the sources of which are sensation (ideas of external things) and reflection (ideas of the mind's own operations) (Essay, II.ii.2; cf. II.i.2-5). Sensation and reflection convey only simple ideas. The mind is then able to act upon these ideas and form, by acts of combination, "complex" ideas such as those of < substance $>$ and <obligation $>$ (Essay, II.xii.I-3). As Locke puts it,

As simple Ideas are observed to exist in several Combinations united together, so the

Mind has a power to consider several of them united together as one Idea; and that 
not only as they are united in external Objects, but as itself has joined them together. Ideas thus made up of several simple ones put together, I call Complex;- -such as are Beauty, Gratitude, a Man, an Army, the Universe; which, though complicated of various simple Ideas, or complex Ideas made up of simple ones, yet are, when the Mind pleases, considered each by it self, as one entire thing, and signified by one name. (Essay, II.xii.I; cf. II.xi.6, II.xii.2-3)

In some ways Kant can agree with this basic picture, for he, like Locke, maintains that our empirical concepts are all constructed by reflection on and abstraction from experience (cf. $J L$ 9:94-95). Kant also agrees that the representation of complex entities requires having complex representations. What separates Kant and Locke are their accounts of the unity of these complex representations. ${ }^{58}$ Locke construes the unity as psychological and linguistic:

Every mixed Mode [i.e. complex idea composed of two or more distinct kinds of simple ideas] consisting of many distinct simple Ideas, it seems reasonable to inquire, whence it has its Unity; and how such a precise multitude comes to make but one Idea, since that Combination does not always exist together in Nature. To which I answer, it is plain it has its Unity from an Act of the Mind combining those several simple Ideas together, and considering them as one complex one, consisting of those parts; and the mark of this Union, or that which is looked on generally to complete it, is one name given to that Combination. (Essay, II.xxii.4)

Kant agrees that the requisite unity is mind-dependent, but denies that this entails that it is merely psychological or linguistic. He instead argues that if scientific knowledge is to be possible, then this unity must be universal and necessary, which entails that it must be based on a priori principles (Bxvii-xviii, B3-4, BI39-40). For Kant, a body of knowledge constitutes a science (Wissenschaft) when there is some principle that organizes it as a whole (MFNS 4:467) and grounds it with apodeictic certainty (MFNS 4:468). Such apodeictic certainty comes only with the a priori nature of the principles constituting the foundation of the science. These a priori principles are not merely prior to the complex representation of objects, but more significantly, they ground and explain why particular complex representations are as they are. Otherwise the unity of the complex would be merely subjective, local, and contingent. There thus must be necessary principles, which Kant locates in the logical laws of judgment (A70-83/B95-I09), that govern the sorts of combination that are allowed. Since Kant describes an object as the most basic sort of complex-namely, "the concept in which the manifold of a given intuition is united" ( $\left.\mathrm{B}_{1} 37\right)$ - the categories, as a priori concepts, are then understood as the most general ways in which thought of an object may occur. Kant makes this clear when he says,

The highest concept from which one is accustomed to begin a transcendental philosophy, is usually the division between the possible and the impossible. But since every division presupposes the concept that is to be divided, a still higher one must be given, and this is the concept of an object in general (taken problematically, leaving undecided whether it is something or nothing). Since the categories are the only concepts that relate to objects in general, the differentiation of an object, as to its being something or

${ }^{58}$ Here again the issue of non-rational representation in animals is relevant; see McLear, "Kant on Animal Consciousness,” esp. §§2-3. 
nothing, must proceed in accordance with the order and guidance of the categories. (A290/B346; my emphasis)

Though Kant's explicit point here is one against traditional scholastic and German metaphysics (cf. Baumgarten, Metaphysica, §§7-8) it is also applicable to Locke, since it illustrates Kant's understanding of the categories as the most general ways of thinking objectively, and with respect to complexes, the most general means of unifying them. ${ }^{59}$

So pace Locke, at least some of modes of combination are a priori rather than derived empirically from received simple ideas. The most obvious example here, with respect to Locke, is the idea of a substance. Locke thinks this idea is an a posteriori one, while Kant argues that it is a priori and plays a structural role in the determination of what elements given in experience may be considered properties or predicates and what can count only as a subject. For example, Kant says in his transition to the argument of the Deduction,

In preparation I wish only to explain the categories. They are concepts of an object in general, by means of which its intuition is regarded as determined with respect to one of the logical functions for judgments. Thus, the function of the categorical judgment was that of the relationship of the subject to the predicate, e.g. "All bodies are divisible."Yet in regard to the merely logical use of the understanding it would remain undetermined which of these two concepts will be given the function of the subject and which will be given that of the predicate. For one can also say: "Something divisible is a body." Through the category of substance, however, if I bring the concept of a body under it, it is determined that its empirical intuition in experience must always be considered as subject, never as mere predicate; and likewise with all the other categories. (B I 28-29; my emphasis)

With the contrast between Locke and Kant's positions in view, we can see how Kant could take his strategy in the B-Deduction as an effective argument against British empiricism (and Locke in particular). By linking the categories with

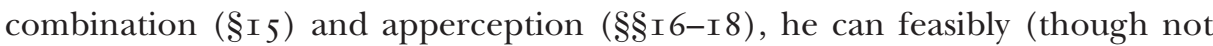
necessarily successfully) argue that the possibility of a proper science depends on our possession of a priori concepts that ground the construction of complex representations or ideas (in Locke's sense of 'idea').

Thus, Kant's argument for the legitimacy of the a priori categories is broadly compatible with an interpretation of the Transcendental Deduction that does not make the unity of intuition as a form of objective representation dependent upon categorical synthesis. The categories make possible the having of complex representations, which govern our grasp of the objects given through intuition, but they need not be understood as making possible our fundamental cognitive connection to the world via intuition.

\section{$3 \cdot 3$ Sense Experience and Discursive Unity}

Let me summarize the ground covered thus far. I have argued that we should firmly distinguish, as Kant himself does, between the form of episodic consciousness marked by the occurrence of an intuition, and the more sophisticated form of

${ }^{59}$ For discussion of the role of the categories as the highest forms of conceptual representation of objects see also Tolley, "The Generality of Kant's Transcendental Logic," esp. §7. 
consciousness of combination of whatever is presented in intuition. The former, though a form of objective representation, is not yet a representation of an object as an object. Hence it is not yet a form of cognition. In order for representation of an object as an object to occur, the subject must combine or otherwise synthesize her intuitive representations such that they may be held together in one consciousness.

In the discussion of Locke above, I argued that both Kant and Locke agree that complex unities cannot be represented in sense experience without some act of the mind that generates unitary representational complexes from otherwise discrete sensory representations of which there is nothing more than episodic consciousness. For Locke, a paradigmatic complex unity is that of a representation of a substance, which requires the representation of a thing (we know not what) that supports qualities (Essay, II.xxiii.2).

Locke's exact view concerning both the nature of substance and our representation of it is contested, but the important point for our purposes is that Kant may be understood to agree with the Lockean position that sense perception gives a subject access to the sensory qualities of objects and thus allows a subject to be, to use a contemporary turn of phrase, "en rapport" with her environment. ${ }^{60}$

Kant disagrees with Locke's account of complex representation by arguing that the proper account of complex ideas requires more than positing a merely psychological and linguistic combination of simple ones. This criticism shows us how the notions of discursive and aesthetic unity interact in Kant's thought. ${ }^{6 \mathrm{I}}$

As I see it, Kant's conception of empirical intuition is one according to which a conscious subject is acquainted with the manifest sensory qualities of objects. ${ }^{62}$ These include such things as shape, hardness, location, color, and so on. These are qualities of objects, and being aware of them allows a subject to be en rapport with the objects in which they inhere, but they are not representations that present an object as having the relevant quality. Consider the sensory grasp of the particular redness of a particular rose, in contrast with the grasp of a particular rose as being red. One can apprehend the redness of the particular rose without thereby apprehending that the rose is red. In apprehending this bit of the rose's redness,

${ }^{6}$ Here I have in mind the capacity for minds to perceptually represent in a manner that extends beyond a mere existential specification of features (e.g. "there is something red and round to my left"), and instead involves a direct representation of a specific object, property, or state-of-affairs (e.g. "that red round patch"). For the contemporary notion of being en rapport with an object or property instantiation, see Kaplan, "Quantifying In”; cf. Bach, Thought and Reference, ch. I.I. However, I do not consider the content of mental states that exemplify such rapport as necessarily being structured "Russellian" propositions. If we understand perception as an acquaintance relation with the surrounding environment, then the "content" of a perceptual experience is just the particular tract of the environment so experienced. For further discussion of this issue see McLear, "Kant on Perceptual Content."

${ }^{6}$ Stern (Structure of the Object, ch. I) makes a similar argument concerning what is at issue between Kant and Locke (and empiricism more generally). However, I do not agree with Stern regarding his claim that for Kant, all relations are ideal, mind-dependent, and thus merely phenomenal (I4, I7), for it seems clear that at least some relations, e.g. moral relations, hold between things in themselves (cf. Ameriks, "Short Arguments"). Hence I disagree with Stern concerning the nature of Kant's argument concerning the role of concepts in cognition.

${ }^{62}$ This use of 'acquaintance' is not necessarily meant to ascribe a Russellian view to Kant; cf. Russell, "Acquaintance and Description." But it is meant to indicate a kind of cognitive relation where a concrete individual is present to the subject in a particularly intimate and immediate way. See McLear, "Kant on Perceptual Content" for further discussion. 
one is representing a particular portion of space and a particular quality as filling or bounding that space. In this way, intuition offers only the awareness of spatially and temporally grouped manifest qualities without any further representation of their underlying unity in a particular object.

Thus, according to my reading of Kant, acquaintance with the empirical qualities of objects is not sufficient for putting one in a position to have empirical knowledge precisely because the presented sensory qualities are not represented as related to one another beyond their possession of a spatial and temporal unity. The fact that various sensible qualities are represented as having a common spatial position (e.g. color, extension, impenetrability) does not mean that there is any representation of some individual as having those qualities. The kind of synthesized empirical cognition that grounds cognition (Erkenntnis) and knowledge (Wissen), in contrast, requires that there be some represented individual grounding the unity of the manifest qualities in a relation mirroring the subject-predicate relation in a propositional judgment. It is precisely in giving this structure to our consciousness of the things with which we are acquainted that our consciousness comes to have discursive unity. Such unity allows the transition from a presentation of something in a spatially and temporally contiguous manner-for example, the perceptual presentation of shape and coextensive color-to the presentation of some particular thing as colored and shaped.

So we have two forms of unity: aesthetic and discursive. An intuition has aesthetic unity in that it presents to consciousness a shaped, located, solid, and colored region of space, the consciousness of which, though episodic, may nevertheless persist over some period of time. Here the subject is consciously en rapport with features of her environment. But she is not yet in a position to make any propositionally structured claims about this tract of her environment. Being in a position to make such claims requires that the second, discursive, form of unity be present in her experience.

Discursive unity binds together the subject's fragmented, episodic representations of the various qualities presented in sensory experience (empirical intuition), and makes possible conscious transitions from an awareness of a sensory quality manifested by some mind-independent object to an awareness of the object manifesting those qualities, that is, a persisting substance. I do not here make any specific claim concerning the exact nature of Kant's argument for how this is possible. That would involve a discussion of the transcendental unity of apperception, among other things. But this sketch of the position shows how Kant could consistently conceive of aesthetic unity as a distinct and independent form of unity, and allow that intuition counts as a form of objective representation despite the absence of synthesis, while nevertheless requiring discursive unity among a subject's states if she is to acquire empirical knowledge.

Before closing I want to address the question of how to understand Kant's claim, quoted in $\S$ I above, that the "same function" that unifies conceptual representations in a judgment also unifies representations in an intuition (A79/ BIO4-5). Intellectualism takes this as indicating that an intuition lacks unity-and thus is not an objective representation-unless synthesized by the understanding. But, as I have argued above, the unity in question here need not be construed as 
one concerning the conditions required for objective representation, but rather only the conditions required for representation of some collection of perceived qualities as belonging to one and the same object. My interpretation agrees with Intellectualism that, as specified by the "same function" passage, there is one fundamental act of mind that explains the capacity both for judgment, in the bringing together of a complex of concepts into a unitary proposition, and in perception, in the bringing together of a complex of sensory representations into a unitary representation of an object $a s$ an object. But my interpretation importantly disagrees with the Intellectualist claim that the role of the understanding in generating such unities implies that intuition depends on the understanding (or the higher cognitive faculties more generally) for its status as a form of objective representation. As I argued in the first half of this paper, intuition has its own form of unity, which grounds its status as an objective representation. Hence, on my view, Kant's concern is not to show that the same discursive acts of mind make all forms of objective representation possible. Instead, he wants to show that the same discursive acts of mind make all representation of objects as objects possible. Representation of an entity as an object requires a unity of consciousness, and Kant argues that such unity depends upon categorical synthesis. According to my suggested interpretation, we can acknowledge all of these points without thereby concluding, as Intellectualism does, that intuition itself, as an objective representation, requires synthesis.

This position obviously requires much filling out, and several issues, such as the necessity with which the categories apply to experience, remain unaddressed. But I hope at least to have shown the intelligibility of a Sensibilist reading of the Transcendental Deduction, and thus the plausibility of interpreting Kant's characterization of cognition (Erkenntnis) as requiring both intuitions and concepts, while nevertheless allowing that each makes a separate and unique contribution (cf. A50-52/B $74-76$ ).

\section{S U M M A R Y}

I have argued that Kant's distinction between the cognitive roles of sensibility and understanding raises a question concerning the conditions necessary for objective representation-representation of features of a mind-independent empirical reality. I distinguished two opposing interpretive positions-namely, Intellectualism and Sensibilism. According to Intellectualism all objective representation depends, at least in part, on the unifying synthetic activity of the mind. In contrast, Sensibilism argues that at least some forms of objective representation, specifically intuitions, do not require synthesis. I then argued that Kant's position concerning the holistic structure of our representations of space and time is incompatible with holding that such representation depends on a synthesis, and thus is incompatible with Intellectualism. This leaves us in an interpretive bind, for though Sensibilism seems to better describe Kant's position in the Aesthetic, Intellectualism seems much closer to his stated position in the argument of the Deduction. So either Kant maintains Sensibilism in the argument of the Aesthetic and Intellectualism in the argument of the Transcendental Deduction (resulting in an incoherent 
position), or we need to reject Intellectualism at the seeming cost of making the argument of the Deduction unintelligible. What is needed is an account according to which intuition has a unity independent of any synthesis, but nevertheless requires a different and further kind of unification in order to count as a fullblown cognition of an object.

I then sketched such an account. I argued that for Kant intuitions represent particular sensory qualities of things in particular spatial and temporal locations. Thus the aesthetic unity of an empirical intuition consists in its representation of, for example, a particular region of space as bounded and colored in specific ways. But such objective representations, though potentially quite complex, are not representations of objects as objects-namely, as individuals that ground the complex of qualities attributed to them. The possibility of this latter form of representation depends on what I have called the "discursive" unity generated by synthesizing intuition, such that a complex of sensory representations is combined into one unitary representational complex via their connection in a unitary trans-episodic state of consciousness. The possibility of knowledge of objects depends on this discursive unity being generated among merely aesthetically unified representations. I argued further that this account makes sense of the Transcendental Deduction's aim to demonstrate the legitimacy of the a priori categories by interpreting the argument there as a reply to Locke (and empiricism more generally) concerning the capacities necessary for the generation of complex representations, including, paradigmatically, representations of substances. Since complex representation is a necessary condition of scientific knowledge of the natural world, the use of the a priori categories in bringing about such complex representations must be legitimate, for without them no knowledge of the natural world would be possible. ${ }^{63}$

\section{B I B L I O G R A P H Y A N D A B B R E V I A T I O N S}

Abela, Paul. Kant's Empirical Realism. New York: Oxford University Press, 2002.

Adams, Robert. Leibniz: Determinist, Theist, Idealist. New York: Oxford University Press, I994. [Leibniz] Allais, Lucy. "Kant, Non-Conceptual Content and the Representation of Space." Journal of the History of Philosophy 47 (2009): 383-4I3. ["Non-Conceptual Content"]

Allison, Henry. Kant's Transcendental Idealism: Revised and Enlarged. New Haven, CT: Yale University Press, 2004. [Idealism]

Ameriks, Karl. "Kant and Short Arguments to Humility." In Kant's Legacy: Essays in Honor of Lewis White Beck, edited by Predrag Cicovacki, I67-I94. Rochester, NY: University of Rochester Press, 200 I. ["Short Arguments"]

Anderson, R. L. "It Adds Up After All: Kant's Philosophy of Arithmetic in Light of the Traditional Logic." Philosophy and Phenomenological Research 69 (2004): 50 I-40. ["It Adds Up"]

— . "The Wolffian Paradigm and its Discontents: Kants Containment Definition of Analyticity in Historical Context." Archiv für Geschichte der Philosophie 87 (2005): 22-74. ["Wolffian Paradigm"]

Aquila, Richard. "The Holistic Character of Kantian Intuition.” In Kant and Contemporary Epistemology, edited by Paolo Parrini, 309-29. Dordrecht: Kluwer Academic Publishers, I994. ["Holistic Intuition"]

${ }_{63}$ Thanks to Lucy Allais, Andrew Chignell, Catharine Diehl, Corey Dyck, Michael Friedman, Till Hoeppner, Des Hogan, Thomas Land, Michelle Kosch, Derk Pereboom, Andrew Roche, Nico Silins, Clinton Tolley, Eric Watkins, two anonymous referees for this journal, and audiences in Princeton and Berlin for many helpful comments and discussions. 
. "Infinitude, Whole-Part Priority, and the Ambiguity of Kantian 'Space' and 'Time.'” In Kant und die Berliner Aufklärung: Akten Des IX. Internationalen Kant-Kongresses, edited by Volker Gerhardt, RolfPeter Horstmann, and Ralph Schumacher, 99-I09. Berlin: Walter de Gruyter, 200I. ["Infinitude"]

Bach, Kent. Thought and Reference. Oxford: Clarendon Press, I987.

Baumgarten, A. G. Metaphysica. Halle: Gebauer, I739.

Bell, David. "The Inaugural Address: Some Kantian Thoughts on Propositional Unity." Proceedings of the Aristotelian Society, Supplementary Volumes 75 (200I): I-I6. ["Propositional Unity"]

Bennett, Jonathan. Kant's Dialectic. London: Cambridge University Press, I974.

Burge, Tyler. Origins of Objectivity. Oxford: Oxford University Press, 2010.

Dickerson, A. B. Kant on Representation and Objectivity. New York: Cambridge University Press, 2004.

Dyck, Corey. "The Divorce of Reason and Experience: Kant's Paralogisms of Pure Reason in Context." Journal of the History of Philosophy 47 (2009): 249-75.

Engstrom, Stephen. "Understanding and Sensibility." Inquiry 49 (2006): 2-25.

Falkenstein, Lorne. Kant's Intuitionism: A Commentary on the Transcendental Aesthetic. Toronto: University of Toronto Press, I995. [Kant's Intuitionism]

Friedman, Michael. Kant and the Exact Sciences. Cambridge, MA: Harvard University Press, I992. [Exact Sciences]

—. "Kant on Geometry and Spatial Intuition." Synthese I 86 (20 I 2): 23 I-55. ["Spatial Intuition"]

George, Rolf. "Kant's Sensationism." Synthese 47 (I98I): 229-255.

Ginsborg, Hannah. "Kant and the Problem of Experience." Philosophical Topics 34 (2006): 59-106.

. "Was Kant a Nonconceptualist?" Philosophical Studies I 37 (2008): 65-77.

Griffith, Aaron M. "Perception and the Categories: A Conceptualist Reading of Kant's Critique of Pure Reason." European Journal of Philosophy 20 (2012): I93-222. ["Perception and the Categories"]

Grüne, Stefanie. Blinde Anschauung. Frankfurt am Main: Vittorio Klostermann, 2009.

Guyer, Paul. "The Deduction of the Categories." In The Cambridge Companion to Kant's Critique of Pure Reason, edited by Paul Guyer, I I 8-50. Cambridge: Cambridge University Press, 20 I0.

- Kant and the Claims of Knowledge. Cambridge: Cambridge University Press, I987.

Haag, Johannes. Erfahrung und Gegenstand. Frankfurt am Main: Vittorio Klostermann, 2007.

Hanna, Robert. "Kant and Nonconceptual Content." European Journal of Philosophy I 3 (2005): 247-90.

Heck, Richard G. "Nonconceptual Content and the 'Space of Reasons."” The Philosophical Review Io9 (2000): 483-523. ["Nonconceptual Content"]

Heidegger, Martin. Phenomenological Interpretation of Kant's Critique of Pure Reason. Bloomington: Indiana University Press, I997. [Interpretation]

Hume, David. A Treatise of Human Nature. Edited by L. A. Selby-Bigge and P. H. Nidditch. Oxford: Clarendon Press, I978.

Janiak, Andrew. "Kant's Views on Space and Time." The Stanford Encyclopedia of Philosophy (Winter 20I 2 Edition). Edited by Edward N. Zalta. URL =<http:/ / plato.stanford.edu/archives/win2OI $2 /$ entries/kant-spacetime/>.

Kant, Immanuel. Kants gesammelte Schriften. Edited by the Akademie der Wissenschaften. Berlin: Georg Reimer (later Walter De Gruyter), I900-.

- The Cambridge Edition of the Works of Immanuel Kant. Edited by Paul Guyer and Allen Wood. Cambridge: Cambridge University Press, I992-.

- Critique of Pure Reason. Translated by Werner S. Pluhar, with an introduction by Patricia Kitcher. New York: Hackett Publishing, I996.

Kaplan, David. "Quantifying In.” Synthese I9 (I968): I78-2I4.

Kitcher, Patricia. Kant's Thinker. New York: Oxford University Press, 20 I I.

Kant's Transcendental Psychology. New York: Oxford University Press, I990.

Land, Thomas. "Kantian Conceptualism." In Rethinking Epistemology, edited by Günter Abel and James Conant, I97-239. Berlin: Walter de Gruyter, 20 I I.

. "Kant's Spontaneity Thesis." Philosophical Topics 34 (2006): I89-220.

—_. "Prescribing Unity to Intuition: Sensibility and Understanding in the Transcendental Deduction." In Law and Peace in Kant's Philosophy: Proceedings of the Tenth International Kant Congress, edited by Guido de Almeida, Valerio Rohden, and Ricardo R. Terra, 2:419-30. Berlin: Walter de Gruyter, 2008. ["Prescribing Unity"]

Leibniz, G. W. F. Discourse on Metaphysics. In Philosophical Essays. Translated and edited by Roger Ariew and Daniel Garber. Indianapolis: Hackett Publishing Company, I989. [Discourse]

- New Essays on Human Understanding. Edited and translated by Jonathan Bennett and Peter Remnant. Cambridge: Cambridge University Press, I996. [New Essays]

Lewis, C. I. Mind and the World-Order: Outline of a Theory of Knowledge. New York: Dover Publications, I929. [Mind and the World-Order] 
Locke, John. An Essay Concerning Human Understanding. Edited by P. H. Nidditch. Oxford: Oxford University Press, I975. [Essay]

Longuenesse, Béatrice. Kant and the Capacity to Judge. Translated from the French by Charles T. Wolfe. Princeton, NJ: Princeton University Press, I998. [Capacity to Judge]

- Kant on the Human Standpoint. Translated from the French by Zahid Zalloua and Nicole Zimek. Cambridge: Cambridge University Press, 2005. [Human Standpoint]

McDowell, John. "Hegel and the Myth of the Given." In Das Interesse des Denkens: Hegel aus Heutiger Sicht, edited by Wolfgang Welsch and Klaus Vieweg, 75-88. Munich: Wilhelm Fink Verlag, 2003. ["Hegel and the Myth"]

—. "Lecture II: The Logical Form of an Intuition." The Journal of Philosophy 95 (I998): 45 I-70. ["The Logical Form of an Intuition"]

. "Lecture III: Intentionality as a Relation." The Journal of Philosophy 95 (I998): 47 I-9I.

["Intentionality as a Relation"]

—. Mind and World. Cambridge, MA: Harvard University Press, I996.

McLear, Colin. "Kant on Animal Consciousness." Philosophers' Imprint I I (20I I): I-I6.

. "Kant on Perceptual Content." Mind (forthcoming).

. "The Kantian (Non)-Conceptualism Debate." Philosophy Compass 9 (20I4): 769-90.

Messina, James. "Kant on the Unity of Space and the Synthetic Unity of Apperception." Kant-Studien IO5 (20I4): 5-40. ["Kant on the Unity of Space"]

Natorp, Paul. Die Logischen Grundlagen der Exakten Wissenschaften. Leipzig: Tuebner, I 9 Iо. [Grundlagen] Onof, Christian, and Schulting, Dennis. "Space as Form of Intuition and as Formal Intuition. On the Note to BI60 in Kant's Critique of Pure Reason." The Philosophical Review (forthcoming). ["Space as Form of Intuition and as Formal Intuition"]

Pereboom, Derk. "Kant on Intentionality." Synthese 77 (I988): 32 I-52.

"Kant's Metaphysical and Transcendental Deductions." In A Companion to Kant, edited by Graham Bird, I 54-68. London: Blackwell, 2006. [Kant's Deductions]

Pippin, Robert. Kant's Theory of Form: An Essay on the Critique of Pure Reason. New Haven, CT: Yale University Press, I982. [Kant's Theory of Form]

Hegel's Idealism: The Satisfactions of Self-Consciousness. Cambridge: Cambridge University Press, I989. [Hegel's Idealism]

Posy, Carl J. "Immediacy and the Birth of Reference in Kant: The Case for Space." In Between Logic and Intuition, edited by Gila Sher and Richard Tieszen, I 5 5-8 5 . Cambridge: Cambridge University Press, 2000. ["Immediacy and Reference"]

Pritchard, H. A. Kant's Theory of Knowledge. Oxford: Clarendon Press, I909.

Rosefeldt, Tobias. Review of Kant on Representation and Objectivity, by A. B. Dickerson. The Philosophical Review I I6 (2007): 468-70. ["Review"]

Russell, Bertrand. "Knowledge by Acquaintance and Knowledge by Description." Proceedings of the Aristotelian Society I I ( I910): Io8-28. [“Acquaintance and Description"]

Schaffer, Jonathan. "Monism: The Priority of the Whole." The Philosophical Review I I9 (2010): 3 I-76. ["Monism"]

—. "On What Grounds What." In Metametaphysics, edited by David J. Chalmers, David Manley, and Ryan Wasserman, 357-83. Oxford: Oxford University Press, 2009.

Sedgwick, Sally. "McDowell's Hegelianism." European Journal of Philosophy 5 (I997): 2I-38.

Sellars, Wilfred. "Kant's Views on Sensibility and Understanding." The Monist 5 I (I967): 463-9I. ["Kant's Views"]

—. Science and Metaphysics: Variations on Kantian Themes. London: Routledge \& Keegan Paul, I968. [Science and Metaphysics]

Shabel, Lisa. "Reflections on Kant's Concept (and Intuition) of Space." Studies in History and Philosophy of Science Part A 34 (2003): 45-57. ["Reflections on Space"]

Smit, Houston. "Kant on Apriority and the Spontaneity of Cognition." In Metaphysics and the Good: Themes From the Philosophy of Robert Merrihew Adams, edited by Samuel Newlands and Larry Jorgensen, I 88-252. Oxford: Oxford University Press, 2009. ["Apriority"]

. "Kant on Marks and the Immediacy of Intuition." The Philosophical Review I09 (2000): 235-66.

Speaks, Jeff. "Is There a Problem About Nonconceptual Content?" The Philosophical Review I I 4 (2005): 359-98. ["Is There a Problem?"]

Stern, Robert. Hegel, Kant and the Structure of the Object. London: Routledge, I990. [Structure of the Object] Strawson, P. F. The Bounds of Sense. London: Routledge, 2002.

Sturm, Thomas, and Falk Wunderlich. "Kant and the Scientific Study of Consciousness." History of the Human Sciences 23 (2010): 48-7I.

Sutherland, Daniel. "The Point of Kant's Axioms of Intuition.” Pacific Philosophical Quarterly 86 (2005): 
I35-59. ["Kant's Axioms"]

Tolley, Clinton. "The Generality of Kant's Transcendental Logic." Journal of the History of Philosophy 50 (2012): 4I7-46.

. "The Non-Conceptuality of the Content of Intuitions: A New Approach." Kantian Review I 8 (2013): 107-36. ["The Non-Conceptuality of the Content of Intuitions"]

Van Cleve, James. Problems From Kant. New York: Oxford University Press, I 999.

Wenzel, Christoph. "Spielen nach Kant die Kategorien schon bei der Wahrnehmung eine Rolle?" Kant-Studien 96 (2005): 407-26. ["Die Kategorien"]

Wunderlich, Falk. Kant und die Bewusstseinstheorien des I 8. Jahrhunderts. Berlin: Walter de Gruyter, 2005. 